University of Nebraska - Lincoln

DigitalCommons@University of Nebraska - Lincoln

P. F. (Paul Frazer) Williams Publications

Electrical \& Computer Engineering, Department

January 1980

\title{
Optics at Texas Tech University: Learning by Doing
}

John F. Walkup

IEEE

P. F. Williams

University of Nebraska - Lincoln, pfw@moi.unl.edu

Martin A. Gundersen

IEEE

Follow this and additional works at: https://digitalcommons.unl.edu/elecengwilliams

Part of the Electrical and Computer Engineering Commons

Walkup, John F.; Williams, P. F.; and Gundersen, Martin A., "Optics at Texas Tech University: Learning by Doing" (1980). P. F. (Paul Frazer) Williams Publications. 10.

https://digitalcommons.unl.edu/elecengwilliams/10

This Article is brought to you for free and open access by the Electrical \& Computer Engineering, Department of at DigitalCommons@University of Nebraska - Lincoln. It has been accepted for inclusion in P. F. (Paul Frazer) Williams Publications by an authorized administrator of DigitalCommons@University of Nebraska - Lincoln. 


\title{
Optics at Texas Tech University: Learning by Doing
}

\author{
JOHN F. WALKUP, SENIOR MEMBER, IEEE, P. FRAZER WILLIAMS, MEMBER, IEEE, AND MARTIN A. GUNDERSEN, \\ MEMBER, IEEE
}

\begin{abstract}
In both the undergraduate and graduate educational programs of the Department of Electrical Engineering at Texas Tech University, students are strongly encouraged to learn by active participation. Both programs have benefited from a vigorous faculty involvement in a wide range of funded research projects in various areas of modern optics.
\end{abstract}

\section{INTRODUCTION}

$\mathrm{U}$ NDERGRADUATE and graduate students in the Depart. ment of Electrical Engineering at Texas Tech University are exposed to modern optics in both the classroom and laboratories. In this paper we discuss a number of innovative features of the various programs and in particular, the use of laboratory experiences. These laboratory experiences have significantly expanded the capabilities of the students and resulted in graduates whose training has been sought by industry. The programs stressed at the undergraduate level include the project laboratories, undergraduate laboratory assistantships, and the NSF-sponsored Undergraduate Research Participation Program, and at the graduate level, a broad spectrum of opticsrelated research programs.

Manuscript received December 31, 1979; revised January 25, 1980.

The authors are with the Department of Electrical Engineering, Texas Tech University, Lubbock, TX 79409.

\section{Undergraduate Programs}

\section{A. The Philosophy}

A key feature in the education of undergraduate electrical engineering students at Texas Tech University is the use of the laboratories to provide intellectually "stretching" experiences. Some five semesters of laboratory experience are oriented around the project laboratory concept. Project laboratories are not the highly structured "cookbook" type, which effectively repeat the concepts presented in classroom lectures; instead, project laboratories teach the student to independently design, construct, test, and present the results of various engineering "projects." In the junior and senior laboratories, many of these projects are in areas where the student has not received formal classroom instruction; therefore, he is required to learn new material almost entirely on his own, with only general guidance provided by his project advisor. We believe this "learning to learn" aspect of the undergraduate laboratory experience to be most important because it prepares the student for engineering practice in an environment where most learning takes place on the job. Additionally, this format makes the project laboratories useful for exposing the students to rapidly developing areas, including many topics in modern optics. 
Besides being exposed to modern optics through the project laboratories and in the classroom, a number of students are exposed through hourly employment as undergraduate laboratory assistants in the various research laboratories. Depending on their abilities, their tasks may include assisting in the specifying and purchasing of research equipment and supplies, construction of research equipment, or actual participation in an ongoing research program. Many of these students have subsequently received regional and national recognition for their work as a result of journal articles, participation in conferences, and participation in the IEEE Student Paper Contest.

A third way in which undergraduate students are exposed to modern optics is through the NSF-sponsored Undergraduate Research Participation Program. Students particpating in this summer program are assigned actual research projects under faculty supervision. The program has introduced optics research to a number of students, not only from Texas Tech, but from other regional schools as well. The details of these programs and others are discussed in the following subsections.

\section{B. Optics Experiments in Undergraduate Laboratories}

A major innovation at Texas Tech University has been the development and implementation of laser and optics experiments for undergraduates. In the late 1960's the faculty recognized that relatively few experiments in these areas had been developed for engineering undergraduates. With the project laboratory structure in mind, Drs. M. Kristiansen and M. Hagler developed, under NSF sponsorship, a relatively comprehensive set of 18 laser and optics project-type experiments for undergraduate engineering students. These were implemented in the junior and senior project laboratories, but they can, in addition, be used in lecture demonstrations. Two reports [1], [2] detailing the experiments were subsequently written and distributed to a large number of institutions, many of which have implemented some of the experiments.

In the mid-1970's, Drs. J. Walkup and M. Hagler noted a need for experiments that would introduce undergraduates to the rapidly developing areas of optical information processing. Again under NSF sponsorship, a set of ten experiments was developed, and a report [3], [4] was prepared describing the experiments and the logistics of setting up an undergraduate optics laboratory. The report describing these projects [3] has also been widely distributed and well received.

A third major effort, led by Drs. F. Williams and T. Krile, currently underway involves the development of a number of optical communications experiments that emphasize the teaching of fiber optics concepts.

These broad-based efforts in optics education have naturally stimulated student interest in optics courses. Over the past eight years we have offered senior electives in such areas as a basic introduction to modern optics, electrooptics, fiber optics, lasers, and quantum electronics. Because of these courses, many students have been motivated to attend graduate school in an area of modern optics.

In accord with our education philosophy, the project laboratories are not coupled to the elective optics courses, so a student may well be introduced to optics through an assigned project laboratory without having been introduced to the con-

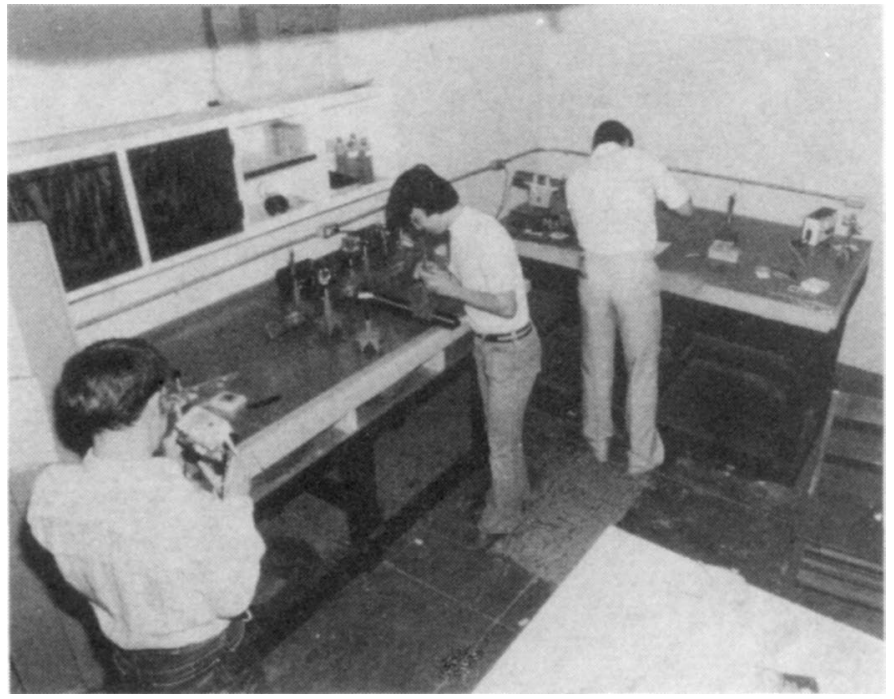

Fig. 1. Students working on optics projects in an undergraduate laboratory.

cepts in a course. The project laboratories thus supplement the course work as well as complement it. This philosophy has been well received by the students and by their future employers.

\section{Undergraduate Participation in Research}

The optics-related research program in the Department of Electrical Engineering is currently very active, and a recent issue of Engineering Education [5] showed the Department to be very highly ranked in terms of research funding per faculty member. The Tech faculty is aware that vigorous faculty participation in research can have deleterious side effects on the quality of undergraduate education and have made strenuous efforts to avoid these effects. Our program for undergraduate participation in research is an example of one area in which undergraduate education has actually benefited significantly from the faculty research activities.

We have found that the opportunity to participate in an active research program can be invaluable to a student. Ideas and techniques learned in the classroom are given form and meaning when used to solve naturally encountered real problems. Working on a problem over an extended period of time develops ability in analytic thinking and problem solving. Finally, even modest success in the research program improves self-confidence, especially when the student is able to take responsibility for his work assignment.

Undergraduate participation in research is accomplished and encouraged through two programs: undergraduate research assistantships, and the NSF-funded Undergraduate Research Participation Program, in which Tech's EE Department has participated for approximately ten years.

The undergraduate research assistantships are generally funded directly through the research program involved. Students are chosen not only for their ability, but also for their motivation and interest. They are assigned projects consistent with their level of ability. Generally, the first assignments are fairly menial, but many students rapidly progress to much more complex projects directly related to the goals of the re- 


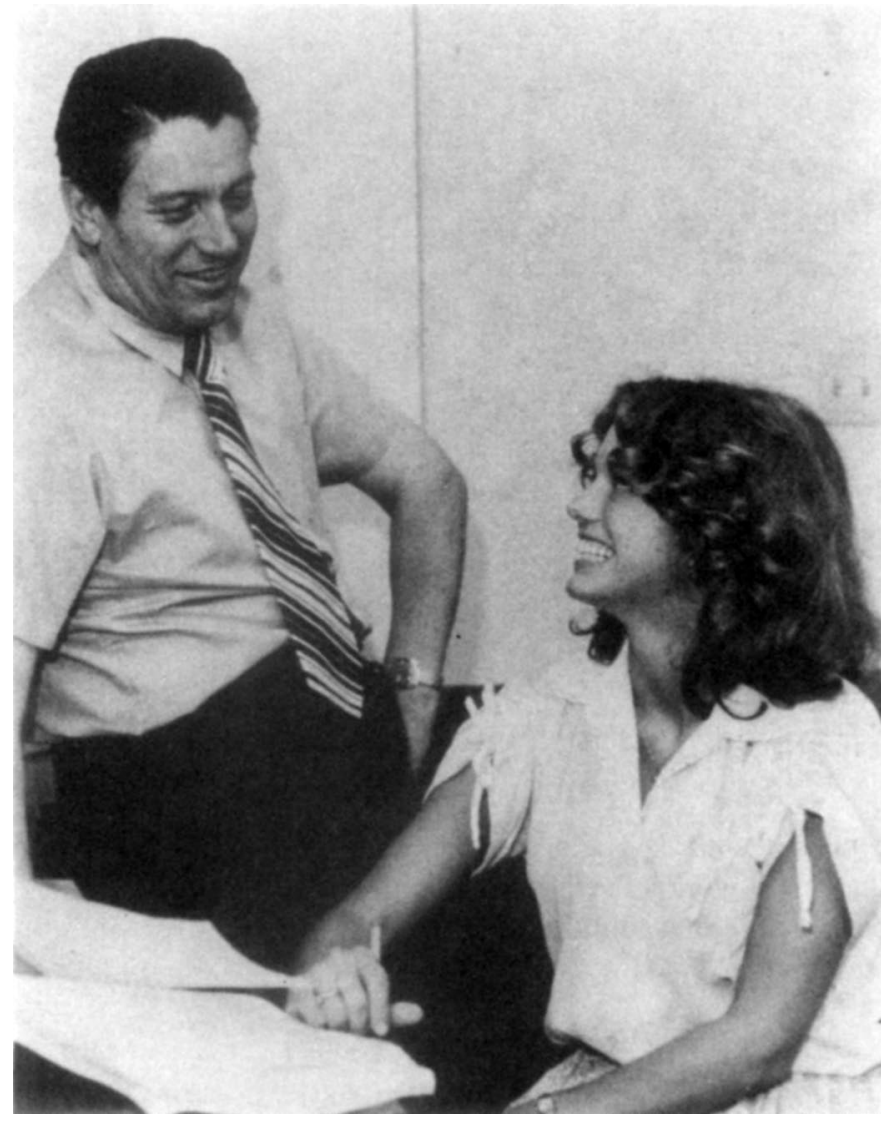

Fig. 2. An NSF Undergraduate Research Participant, J. Scott, discusses her summer research project with Dr. R. H. Seacat, Chairman of the Texas Tech Department of Electrical Engineering.

search program. For example, a Texas Tech undergraduate discovered the first university $16 \mu \mathrm{m}$ laser system suitable for use in uranium isotope separation. Another undergraduate is conducting an investigation of the optical fluorescence spectrum of impurity and defect states in III-V semiconductors. A third is designing and constructing a rather sophisticated microprocessor-based signal averager for use in a specialized application, and a fourth is troubleshooting a digital image processing system.

The NSF-funded Undergraduate Research Participation Program allows students to spend a summer working on one specific project. The program provides student salaries as well as minimal expenses for supplies. Projects are generally an integral part of an ongoing research program, and are designed to be self-contained, with clear, attainable goals. Projects have ranged from the designing of plasma probes to the performing of experiments on novel optical data processors. Besides the direct research activity, students meet for weekly talks by faculty or other speakers on technical topics of interest, give seminars on their own work, and take one or two field trips to scientific establishments in the region, such as Sandia Laboratories or the Los Alamos Scientific Laboratories.

To round out the students' experiences in these research participation programs, we strongly encourage them to enter the IEEE Student Paper Contest. Besides the thrill of competition, they acquire important experience in writing and public speak ing. Students from Texas Tech have done well in this contest, placing in the top three in the Region V contest in three of the past four years.

\section{Graduate Programs}

\section{A. Philosophy}

A major thrust of the graduate education program in the Department of Electrical Engineering at Texas Tech is to get the students involved as soon and as deeply as possible in active research programs. We believe the most important thing we can teach a student is how to learn for himself, and the best way to acquire this skill is through practice-learning ideas and concepts needed to solve problems encountered in carrying out a research project. Formal classroom experience provides useful knowledge but does little to develop this important skill since it involves a somewhat artificial and highly structured environment. Accordingly, a thesis is required of all masters degree candidates, and all graduate students, even those in their first year, are strongly encouraged to become involved in a research program in the Department.

It is hoped that the student's intellectual capabilities will mature in the graduate program. If his education were entirely dependent on his research experience, however, there would be large holes in his knowledge of existing techniques and concepts for solving problems in his field. Formal graduate classes are intended to overcome this problem and insure that every graduate has the full complement of basic problem-solving tools. The research experience is intended to enable him to develop skills in applying these tools.

Graduate students are required to take a number of general courses. Electrical engineering is arbitrarily divided into six general areas, and a masters student is required to take at least one course in four of these areas. Additionally, more specialized courses are also offered where needed to complement a broad area of research activity.

To properly implement a graduate program utilizing this philosophy, vigorous faculty participation in research programs of current interest is mandatory. Fortunately, this requirement is met at Texas Tech. The following subsections contain brief descriptions of the optics-related research programs currently under way at Texas $T e c h$. They indicate the range and depth of our commitment to an active research program in optics.

\section{B. Optical Systems Research}

Optical systems research at Texas Tech centers around the application of systems concepts and techniques to a variety of problems in optical data processing, holography, optical communications, digital image processing, and pattern recognition. Some of the facilities used in the research programs include optical stable tables; argon-ion and helium-neon CW lasers; optical benches, mounts, and accessories; optical spectrum analyzers; electrooptical and electromechanical beam scanners; electronically scanned diode arrays; and darkrooms for photographic processing. In addition, a high-quality facility for digital image processing and display is presently being assembled. Funding for the various research projects in this area have been provided by the National Science Foundation, 


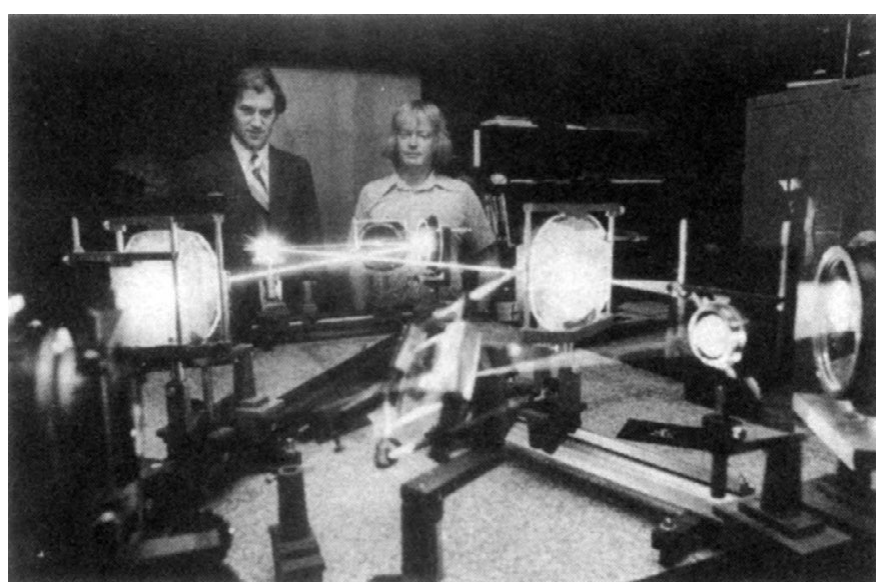

Fig. 3. Dr. J. Walkup and graduate student M. Jones, with a system employing holograms to represent space-variant optical systems.

Air Force Office of Scientific Research, the Joint Services Electronics Program, and the State of Texas.

Optical Information Processing: The term "optical information processing" refers to the manipulation of large amounts of data (often in parallel) at the speed of light. At Texas Tech, Profs. Walkup, Hagler, and Krile and their students have been looking into extensions of conventional optical signal processors in novel areas such as performing space-variant operations that are the spatial analogs of the time-variant operations discussed in electrical engineering texts on systems theory. In optical processing it appears that many types of optical computing operations that one might want to perform (such as various integral transforms) are space-variant. This important area is being considered for both one-dimensional and twodimensional signals, using both coherent illumination (laser light) and incoherent illumination. The results to date include a generalized one-dimensional coherent space-variant processor, a sampling theorem for representing shift-variant systems, a coded reference beam approach for using a multiplexed hologram to optically represent a spatially-sampled two-dimensional space-variant system, and a technique for optically evaluating the so-called radar ambiguity function used to characterize the range-velocity discrimination characteristics of radar signals. If one can use a computer-generated hologram to perform the same operation as a complicated system of lenses, which is one problem presently under investigation, coherent optical processors may have an even brighter future. A number of the M.S. and Ph.D. students who have worked in the Optical Systems Laboratory have presented papers at IEEE and other professional society meetings over the past eight years.

An important problem area with optical processors is the development of spatial light modulators as "interfaces" between the electrical signal inputs and the optical signals to be processed by an optical processor. Prof. Krile is examining the possible uses of a magnetooptical device as an interface with an optical processor. He is also interested in fiber-optic acoustic sensors and other applications of fiber optics in optical communications and signal processing. Prof. Hagler has been looking into techniques for placing a laser in a feedback loop so as to achieve an optical operational amplifier. This device would be a two-

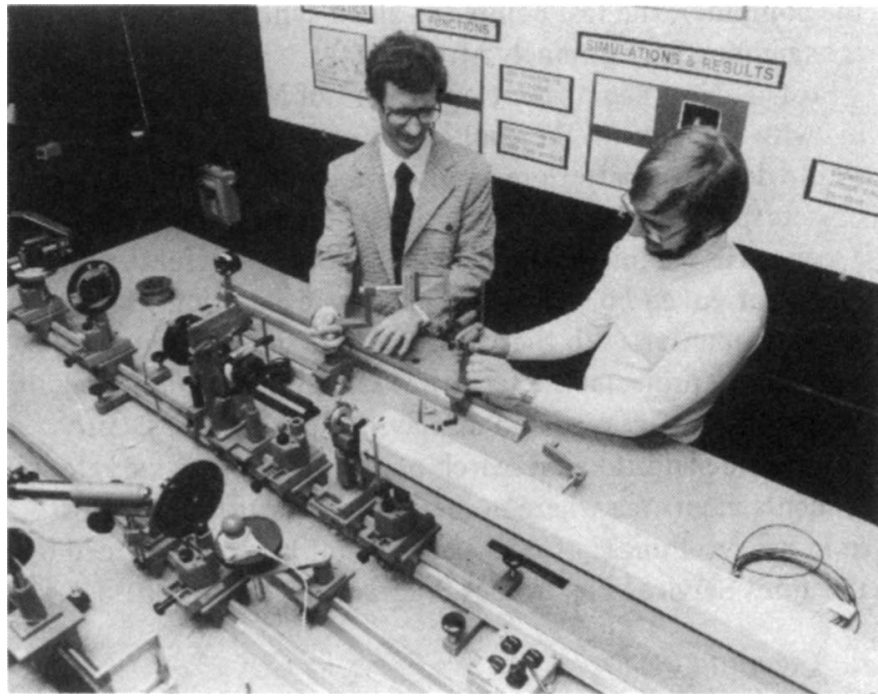

Fig. 4. Dr. T. Krile and graduate student C. Irby investigate the use of computer-generated holograms in optical signal processors.

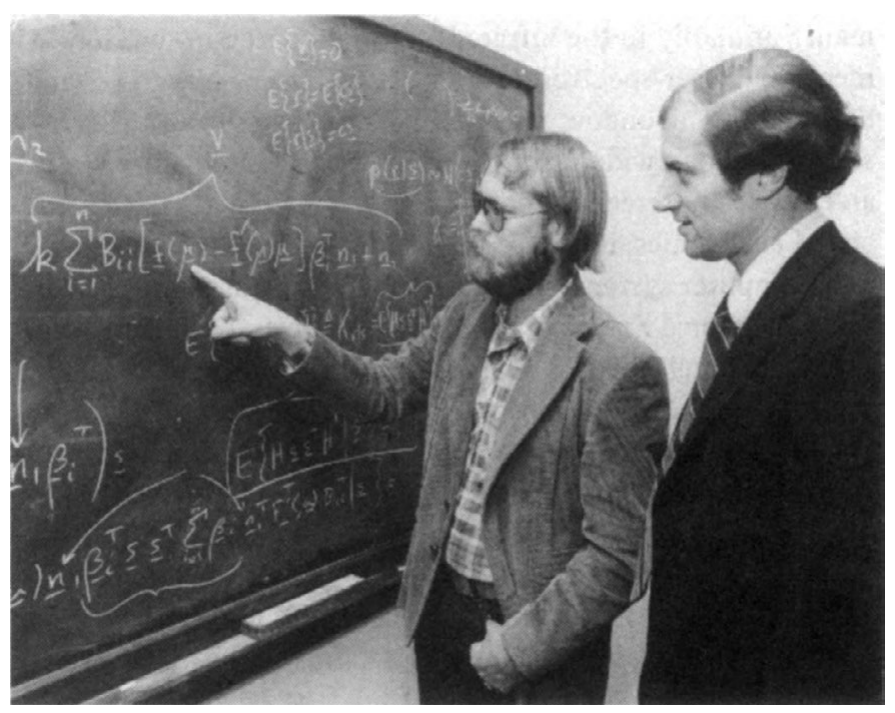

Fig. 5. Dr. J. Walkup and graduate student G. Froehlich discuss a new approach to estimating signals in signal-dependent image noise.

dimensional analog of the familiar electronic operational amplifiers. Such devices would be capable of real-time filtering of blurred images, solving two-dimensional differential equations, etc.

Digital Image Processing: In the areas of digital image processing and pattern recognition, several projects are under way. Profs. Walkup and Krile and their students are looking into the optimal suppression of signal-dependent noise sources, such as film grain noise and photoelectronic shot noise. Since the strength of these noise sources differs as the signal varies spatially, new estimation and detection techniques must be developed for dealing with the problems. Other applications of the results lie in areas such as Rayleigh fading in communications, and magnetic tape recording noise. Prof. J. Murray is investigating new techniques for designing and implementing digital filters for applications in digital image processing. Since digital filters traditionally require considerable time to synthesize on 
the computer, the fast computer-aided synthesis techniques he is examining are extremely attractive.

Prof. T. Newman of the Department of Mathematics is working with students on the application of group theory principles to the design of pattern recognition techniques for tracking objects that may differ in size, orientation, or brightness within a scene. His techniques appear much more powerful than many of the current ad hoc statistical pattern recognition techniques.

In conjunction with these image processing and pattern recognition projects, the faculty is assembling a quality facility for digitally processing and displaying images. The facility will provide additional research opportunities for graduate students in an area where numerous job opportunities exist in industry. Funding for this equipment is being provided by the Joint Services Electronics Program at Texas Tech.

\section{Quantum Electronics}

Quantum electronics is an exciting, rapidly growing area of electrical engineering in which the Department maintains a strong commitment. Faculty research interests span a wide range. Major programs under way include new laser development (primarily in the infrared), infrared detector development, and laser-spectroscopic investigations of impurities and defects in semiconductors. Facilities used to support this research include a wide range of infrared and visible pulsed lasers, an electrically screened room, a variety of detectors and associated electronics, infrared and visible spectrometers, and two minicomputer systems. Research in these areas is supported by the National Science Foundation, the US. Department of Energy through the Los Alamos Scientific Laboratories, and the Research Corporation.

New Laser Development: Work in this field is carried out by Profs. M. Gundersen and F. Williams, and supported primarily by the Department of Energy. It proceeds in close collaboration with the laser isotope separation group at Los Alamos. A variety of laser systems are used in support of this work. Two laser systems are used in searches for new, electrically pumped lasers. One of the first $16 \mu \mathrm{m}$ lasing systems suitable for use in uranium isotope separation was discovered using one device, and a number of new lasing transitions of the noble gases in the 7 to $8 \mu \mathrm{m}$ range have recently been discovered using the other.

A strong effort is directed toward utilizing optical pumping techniques to develop new lasers in the mid-infrared. A novel, single-frequency, tunable, $\mathrm{CO}_{2}$, TEA laser is used to provide a high-quality pump source in the 9 to $11 \mu \mathrm{m}$ range. This facility allows the study of the basic physical features of the optical pumping process as they relate to the stability and efficiency of optically-pumped lasers. Besides this work, new optically pumped lasers in the mid-infrared are sought using either the $\mathrm{CO}_{2}$ pump or a $4 \mu \mathrm{m}$ HF laser pump.

Infrared Detector Development: Efficient, sensitive detectors of infrared radiation are presently needed for a number of applications ranging from infrared astronomy to night vision devices. A promising system of this type has been invented by Prof. Gundersen. The detector operates by frequency upconverting the infrared radiation to visible light, which may be efficiently detected either with conventional photodevices or

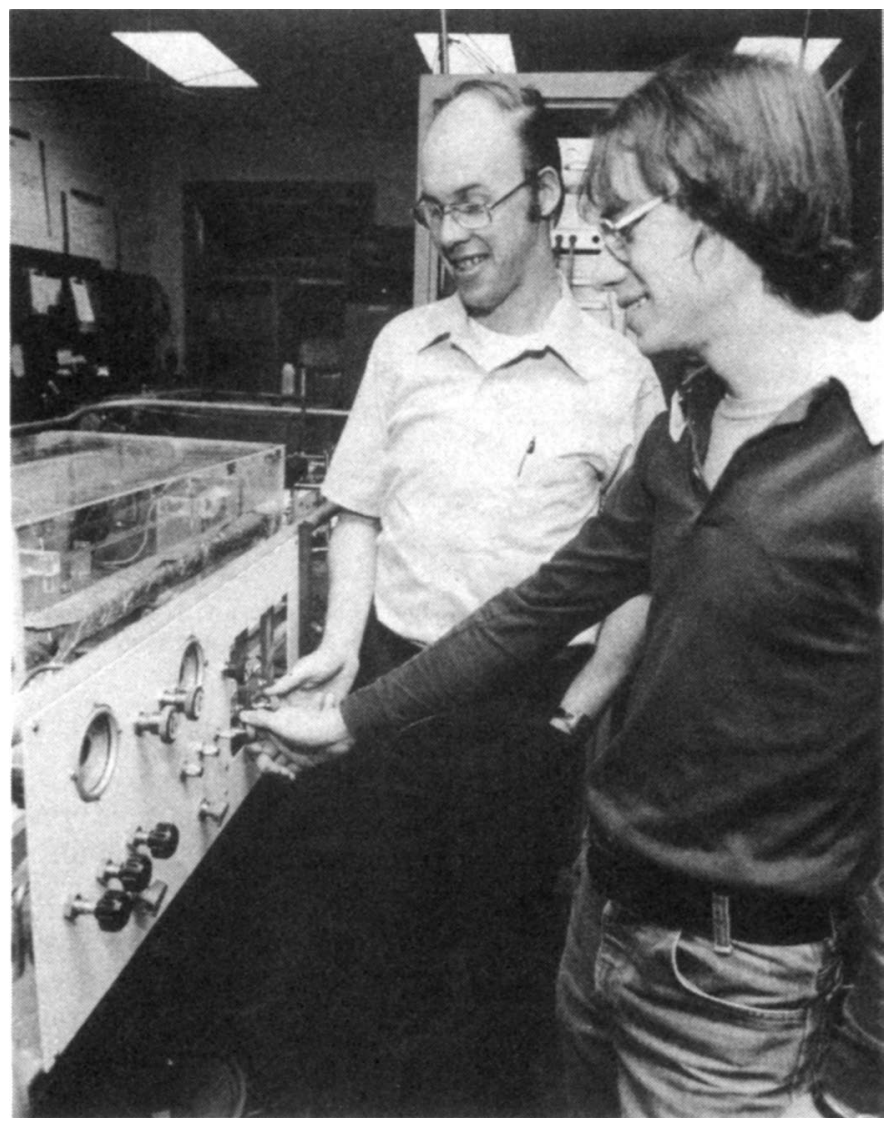

Fig. 6. Dr. F. Williams and graduate student R. Dougal adjust gas flow in a specially constructed $\mathrm{CO}_{2}$ laser.

by eye. A great deal of development work remains to be done, and such work is currently under way. This research is supported primarily by the National Science Foundation.

Impurity and Defect States in Semiconductors: Impurities and defects play an important (often detrimental) role in the operation of many semiconductor devices, but the detailed physical properties of the electronic states of many such centers are poorly known. For example, GaAs is commonly used in fast microwave and light emitting devices. Impurity-related states such as deep traps can have deleterious effects on device speed and efficiency, but little is known about these states. For these reasons, a research program to investigate these defect states is being pursued by Profs. Gundersen and Williams. Spectroscopic analysis of photoluminescence from doped semiconductor samples is the main experimental technique used in this work. A unique feature of this research is the use of two excitation lasers. One laser, usually in the visible or near infrared, is used to populate an electronic state of a defect complex, and then a second laser, usually in the mid-to-far infrared, is used to probe the excited state structure of the complex. This work is proceeding under close cooperation with several semiconductor device groups at Texas Instruments, Inc.

\section{Plasma and Pulsed Power Applications}

Various optical diagnostic techniques are being used for a wide range of plasma studies at Texas Tech. Lasers are also being used to trigger spark gap closure in two separate studies. Much of the spark gap work is carried on under the Coordi- 


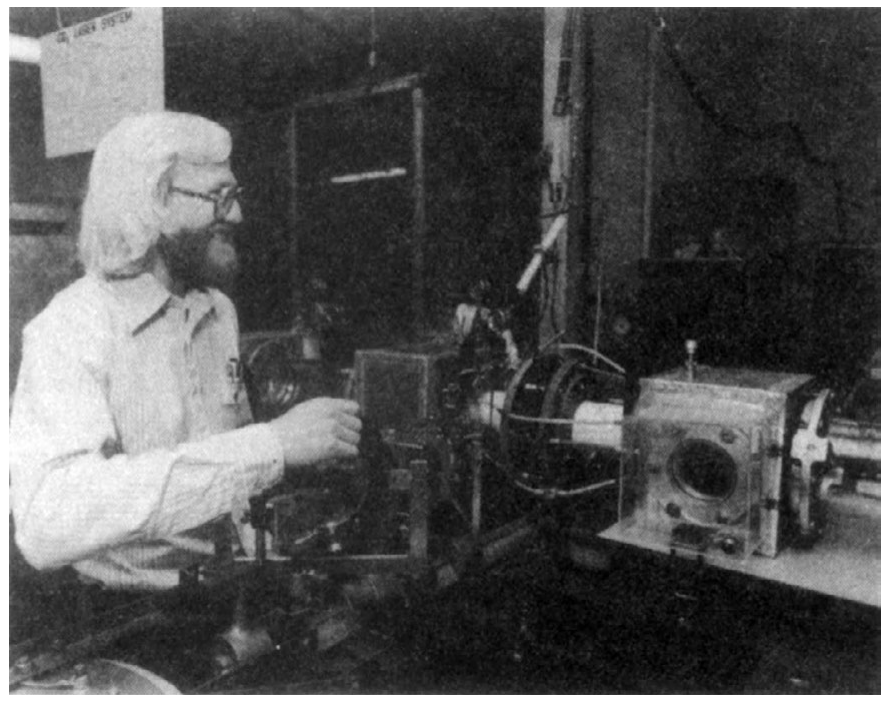

Fig. 7. Graduate student R. Druce aligns a beamsplitter in a laser heated plasma experiment in the Plasma Laboratory.

nated Research Program in Pulsed Power Physics, sponsored by the Air Force Office of Scientific Research. Other work is sponsored by the National Science Foundation, Lawrence Livermore Laboratories, Sandia Laboratories, and the Research Corporation. Faculty involved in this work include Profs. F. Williams, M. Gundersen, M. Kristiansen, E. Kunhardt, M. Hagler, L. Hatfield, and K. Schönbach.

Laser-Triggered Electrical Discharges: This effort is motivated by the need for fast low-jitter high-current switches. At present, spark gaps are the best solution for many such switching problems, but they often suffer from long closure times and excessive temporal jitter. Laser triggering of these gaps can in many cases significantly reduce closure times and temporal jitter, making such gaps advantageous in a number of applications. One effort at Texas Tech is aimed at studying the characteristics of laser-triggered breakdown as a function of the various parameters important to the process, such as gap voltage, gas pressure or chemical constitution, and laser power and focusing. Another effort is examining the use of fiber optics to introduce the laser trigger into the gap and to provide optical delay lines for the trigger.

Optical Diagnostics of Plasmas: Optical diagnostics are useful for studying plasmas because they are generally nonperturbing and fast. A number of research programs at Texas Tech utilize these techniques. In one study, optical spectra from a laser-triggered discharge are obtained using a computercontrolled, time-gated, optical multichannel analyzer that may be coupled to a variety of spectrographs. In another area, optical spectroscopy is used as a diagnostic for the Texas Tech Tokomak, and for a laser heating experiment in which a plasma is heated through parametric interaction with a powerful $\mathrm{CO}_{2}$ pulsed laser. In another area, laser-induced fluorescence spectroscopy is being used as another time-resolved plasma diagnostic. Additionally, a program in multiphoton ionization spectroscopy has recently been initiated to study the importance of multiphoton ionization processes in laser triggering of spark gaps and in streamer propagation in high voltage breakdown.

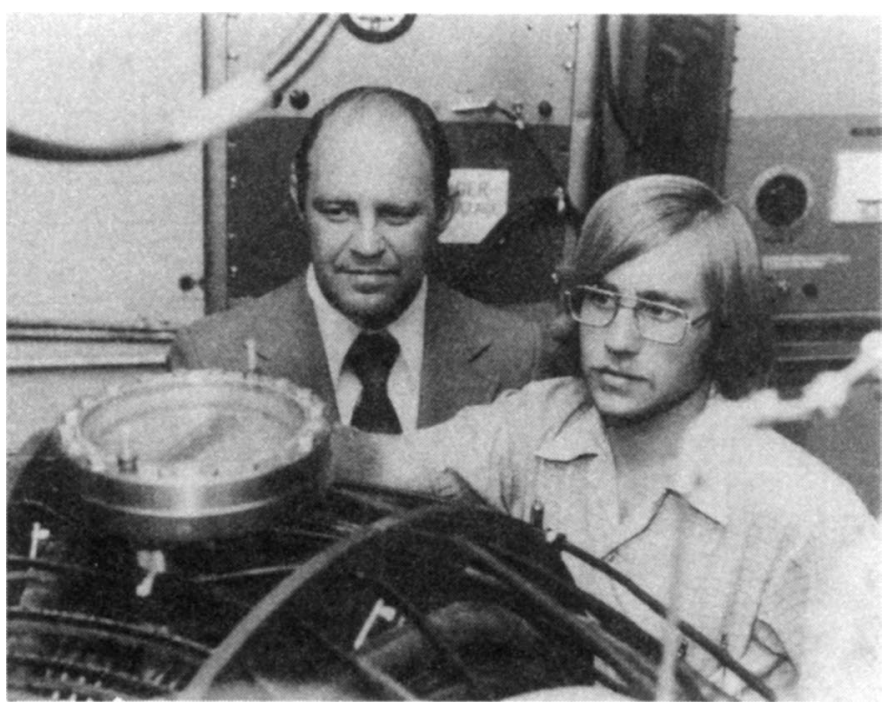

Fig. 8. Dr. M. Hagler and graduate student S. Beckerich, working with the Texas Tech Tokamak. The viewing port in the lower left corner is for optical diagnostics.

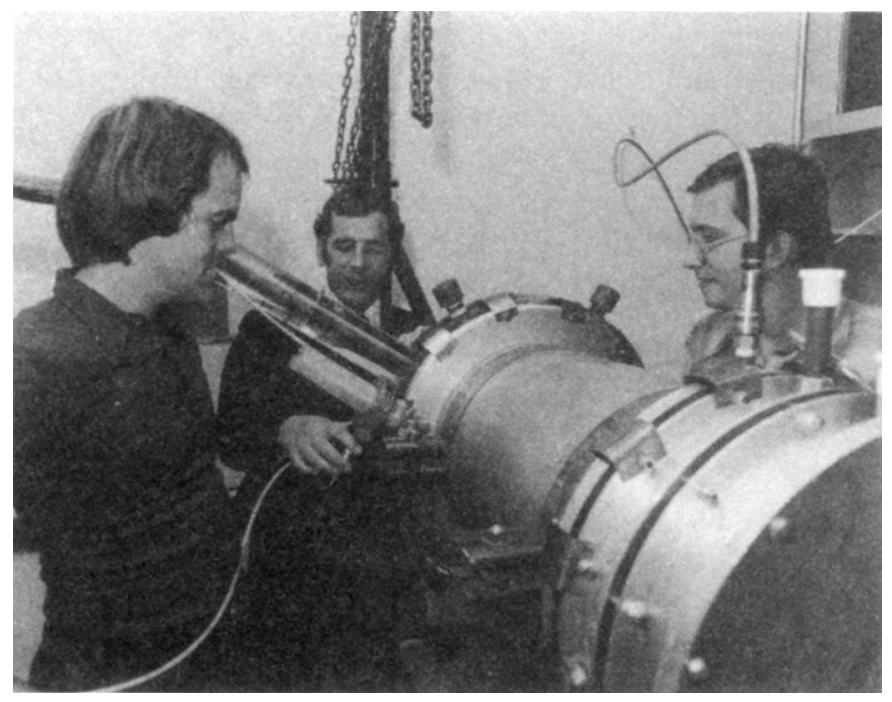

Fig. 9. Dr. L. Hatfield and graduate students L. Gordon and G. Wood discuss the behavior of a laser-triggered spark gap experiment in the Switching Laboratory.

Fast streak photography is used to obtain information about electrical breakdown in a large electron beam triggered spark gap. Finally, optical interferometry and Thompson scattering are used to obtain electron density information.

\section{E. Crosbyton Solar Power Project}

The objective of the Crosbyton Solar Power Project, headed by Prof. J. D. Reichert, is to develop the fixed-mirror distributedfocus (FMDF) concept for production of electricity in Crosbyton, TX, some 40 miles east of Texas Tech University. In this design, a large, fixed, spherical mirror concentrates solar radiation onto a small, mobile boiler that moves to follow the solar line image as the sun moves across the sky. Steam produced in the boiler is used to generate electrical power in a conventional way. 


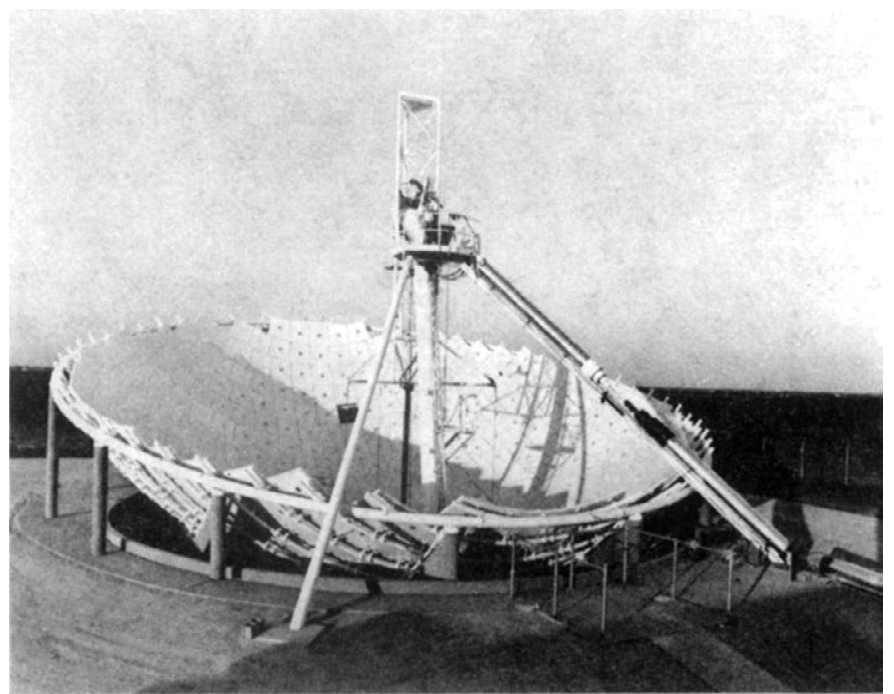

Fig. 10. The $65 \mathrm{ft}$ diameter prototype (analog design verification system) for the Crosbyton Solor Power Project located in Crosbyton, TX. Dr. J. D. Reichert is the project director.

A $65 \mathrm{ft}$ diameter prototype system has been constructed and is currently being tested. Extensive studies and experiments involving optical-thermal-fluid calculations, radiant and joule heating boiler test facilities, boiler design, and the reflectivity, alignment, stability, and weathering characteristics of the mirrors are being conducted. Information obtained from this program will be used to design the full-scale system for the city of Crosbyton. The final system will produce $5 \mathrm{MW}$ of electrical power, will consist of ten $200 \mathrm{ft}$ diameter solar collectors, and will cost about $\$ 22$ million. The project is funded by the Department of Energy.

\section{SUmmary}

Both the undergraduate and graduate students in the Department of Electrical Engineering at Texas Tech University are introduced to modern optics using approaches that stress learn. ing by active involvement in either project laboratories or research laboratories. This approach, which strongly emphasizes the students' responsibility to learn with appropriate faculty guidance, has proven to be successful. A vigorous research program has been shown to reap benefits for both undergraduate and graduate students.

\section{ACKNOWLEDGMENT}

The authors are pleased to acknowledge the significant support of the Directorate for Science Education of the National Science Foundation for the support of several projects aimed at developing undergraduate optics laboratories and laboratory projects and for the support of student research under the Undergraduate Research Participation Program. The opticsrelated research programs have been funded by the Air Force Office of Scientific Research, the Joint Services Electronics Program, Office of Naval Research, Army Research Office, Department of Energy, Los Alamos Scientific Laboratories, Sandia Laboratories, Lawrence Livermore Laboratories, Research Corporation, National Science Foundation, Texas Instruments, Inc., and the State of Texas. Their support is gratefully acknowledged.

\section{REFERENCES}

[1] L. N. Peckham, M. O. Hagler, and M. Kristiansen, "Laser experiments for undergraduate electrical engineering students," Texas Tech University, Lubbock, TX, Tech. Rep. 1, NSF Grant GY-4761, June 1969.

[2] G. M. Molen, C. R. Parten, M. O. Hagler, and M. Kristiansen, "Laser experiments for undergraduate electrical engineering students," Texas Tech University, Lubbock, TX, Tech. Rep. 2, NSF Grant GY-4761, May 1971.

[3] G. K. Frochlich, J. F. Walkup, and M. O. Hagler, "Optical information processing experiments for undergraduate engineers," Texas Tech University, Lubbock, TX, Tech. Rep., NSF Grant SER 75-17673, Jan. 1977. Copies of the report are available either from the authors or the National Technical Information Service, Springfield, VA 22151 (accession no. PB 264356).

[4] G. K. Froehlich, J. F. Walkup, and M. O. Hagler, "A set of optical information processing experiments," IEEE Trans. Educ., vol. E21 , pp. 4-7, Feb. 1978.

[5] "Engineering college research and graduate study," Eng. Educ., vol. 69, Mar. 1979.

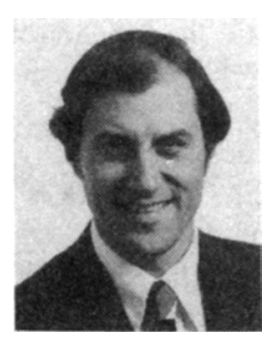

John F. Walkup (S'62-M'71-SM'78) received the A.B. degree in engineering science and the B.E.E. degree in electrical engineering from Dartmouth College, Hanover, NH, in 1962 and 1963 , respectively. He received the M.S., Engineer, and Ph.D. degrees in electrical engineering from Stanford University, Stanford, CA, in 1965,1969 , and 1971 , respectively.

Since 1971 he has been a member of the faculty of the Department of Electrical Engineering, Texas Tech University, Lubbock, TX, where he is currently an Associate Professor. His research interests include optical information processing, holography, image processing, and communication theory. He has introduced undergraduate and graduate course work and laboratory work in the optics area at Texas Tech. He has also served as a consultant to industrial firms and government agencies.

Dr. Walkup is a member of the Society of Photo-Optical Instrumentation Engineers, the American Society for Engineering Education, and is a Fellow of the Optical Society of America. He is also a member of Sigma Xi, Phi Beta Kappa, Eta Kappa Nu, and Tau Beta Pi.

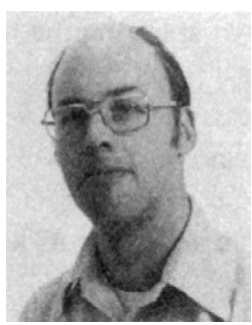

P. Frazer Williams (M'77) received the B.S. degree in physics from the California Institute of Technology, Pasadena, in 1967, and the $\mathrm{Ph} . \mathrm{D}$. degree in electrical engineering from the University of Southern California, Los Angeles, $\mathrm{CA}$, in 1973.

He was a member of the technical staff at Bell Laboratories from 1972 to 1974 , a member of the faculty of the Physics Department, University of Puerto Rico, Río Piedras, Puerto Rico, from 1974 to 1976 , and has been on the faculty of the Department of Electrical Engineering, Texas Tech University, Lubbock, since 1976, where he is currently is an Associate Professor. His research interests include Raman spectroscopy of solids and gases, fluorescence spectroscopy of semiconductors and gaseous plasmas, electrical breakdown physics, and photoelectrochemistry as it relates to solar energy conversion and storage applications.

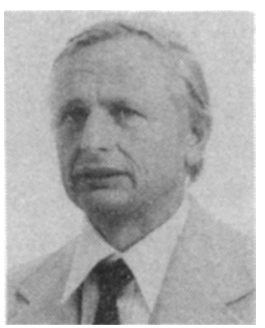

Martin A. Gundersen (M'73) received the B.A. degree in physics from the University of California, Berkeley, in 1965, and the M.A. and Ph.D. degrees in physics from the University of Southern California, Los Angeles, in 1967 and 1972 , respectively.

He has been a member of the faculty in the Department of Electrical Engineering, Texas Tech University, Lubbock, since 1973, and is currently an Associate Professor. His research interests include infrared and visible laser development, optical spectroscopy of semiconductors, infrared up-conversion, and electrical discharge physics. 